\title{
Determinação de 25-hidroxivitamina D2 e D3 em plasma por CLAE-DAD
}

Primeira submissão em 11/01/12 Última submissão em 11/01/12 Aceito para publicação em 16/07/12 Publicado em 20/10/12

\section{Determination of 25-hidroxy-vitamin D2 and D3 in plasma by HPLC-DAD}

unitermos

Vitamina D3

25-hidroxivitamina D3

25-hidroxivitamina D2

CLAE
Daiana Manuele Kich'; Fabiana Aparecida de Souza Vieira²; Mauricio Bassuino3; Rafael Linden ${ }^{4}$

\section{resumo}

Introdução: $O$ interesse pela vitamina $D$ nos últimos anos teve aumento significativo. Estudos epidemiológicos realizados têm demonstrado um crescente aumento da deficiência de vitamina $D$ entre a população. O marcador diagnóstico de escolha para determinar os níveis de vitamina D é a concentração de 25-hidroxivitamina D (25(OH)D), com suas frações D2 $\left(25(\mathrm{OH}) \mathrm{D}_{2}\right)$ e D3 $\left(25(\mathrm{OH}) \mathrm{D}_{3}\right)$. Objetivo: Desenvolver uma metodologia analítica empregando cromatografia líquida de alta eficiência com detector de arranjo de diodos (CLAE-DAD) para a determinação de $25(\mathrm{OH}) \mathrm{D}_{3}$ e $25(\mathrm{OH}) \mathrm{D}_{2}$ em plasma. Materiais e métodos: $25(\mathrm{OH}) \mathrm{D}_{3}$ e $25(\mathrm{OH}) \mathrm{D}_{2}$ foram extraídos das amostras de plasma com hexano, utilizando-se dodecafenona como padrão interno (PI). Utilizou-se coluna analítica ACE $5 \mathrm{C} 18$ com partículas de $5 \mu \mathrm{m}$ e dimensões de $150 \times 4,6 \mathrm{~mm}$, fase móvel metanol-água (80:20; v/v) e quantificação em $265 \mathrm{~nm}$. Resultados: A exatidão foi entre 98,4 e $107,5 \%$. A precisão intraensaios esteve entre $6,5 \%$ e $9,2 \%$ para $25(\mathrm{OH}) \mathrm{D}_{3}$ e entre $3,7 \%$ e $8,7 \%$ para $25(\mathrm{OH}) \mathrm{D}_{2}$. A precisão interensaios esteve entre $2,9 \%$ e $6 \%$ para $25(\mathrm{OH}) \mathrm{D}_{3}$ e entre $4 \%$ e $4,5 \%$ para $25(\mathrm{OH}) \mathrm{D}_{2}$. O limite inferior de quantificação foi $10 \mathrm{ng} / \mathrm{ml}$. As concentrações encontradas em amostras de 32 pacientes idosos estiveram entre 10,1 e $32,4 \mathrm{ng} / \mathrm{ml}$, caracterizando deficiência de vitamina $D$ nesse grupo. Discussão: O método foi capaz de quantificar $25(\mathrm{OH}) \mathrm{D}_{2}$ e $25(\mathrm{OH}) \mathrm{D}_{3}$ com uma preparação de amostra relativamente simples e rápida. O método foi seletivo, com separação adequada dos metabólitos e do padrão interno e sem presença de interferentes. Conclusão: O método desenvolvido apresenta desempenho analítico adequado e pode ser aplicado em condições clínicas. abstract

Introduction: The interest in vitamin D has increased significantly in recent years. Epidemiological studies conducted over the past 25 years have shown a steady increase in vitamin $D$ deficiency. The diagnostic marker of choice to determine vitamin $D$ levels is the concentration of 25-hidroxy-vitamin $D(25(\mathrm{OH}) D)$ in the fractions $D 2\left(25(\mathrm{OH}) D_{2}\right)$ and $D 3\left(25(\mathrm{OH}) D_{3}\right)$. Objective: To develop an analytical method using high-performance liquid chromatography with diode-array detection (HPLC-DAD) for the determination of $25(\mathrm{OH}) \mathrm{D}_{2}$ and $25(\mathrm{OH}) \mathrm{D}_{3}$ in plasma. Materials and methods: $25(\mathrm{OH}) \mathrm{D}_{3}$ and $25(\mathrm{OH}) \mathrm{D}_{2}$ were extracted from plasma samples with hexane and dodecaphenone was used as internal standard. The separation was performed in an ACE 5 C18 column, with particle size of $5 \mu \mathrm{m}(4,6 \times 150 \mathrm{~mm})$, mobile phase methanolwater (80:20, v/v) and quantification at $265 \mathrm{~nm}$. Results: Accuracy was in the range of 98.4 to $107.5 \%$. Intra-assay precision was between 6.5 and $9.2 \%$ for $25(\mathrm{OH}) \mathrm{D}_{3}$ and 3.7 and 8.7 for $25(\mathrm{OH}) \mathrm{D}_{2}$. Inter-assay precision was between 2.9 and $6 \%$ for $25(\mathrm{OH}) D_{3}$ and 4 and 4.5 for $25(\mathrm{OH}) D_{2}$. The limit of quantification was $10 \mathrm{ng} / \mathrm{l}$. Concentrations of $25(\mathrm{OH}) \mathrm{D}_{3}$ in samples from 32 elderly patients were between 10.1 and $32.4 \mathrm{ng} / \mathrm{ml}$, characterizing vitamin $D$ deficiency in this group. Discussion: The method allowed the quantification of $25(\mathrm{OH}) \mathrm{D}_{2}$ and $25(\mathrm{OH}) \mathrm{D}_{3}$. Furthermore, the sample preparation was relatively simple and fast. The method was selective with an adequate separation of metabolites and internal standard with no interfering substances. Conclusion: Not only did the developed method show suitable analytical performance, but it may also be applied in clinical conditions. key words

Vitamin D3

25-hidroxy-vitamin D3

25-hidroxy-vitamin D2

HPLC

\footnotetext{
1. Farmacêutica.

2. Mestre em Qualidade Ambiental; professora assistente da Universidade Feevale.

3. Biomédico.

4. Doutor em Biologia Celular e Molecular; professor titular da Universidade Feevale.
} 


\section{Introdução}

A deficiência de vitamina $D$ é comum em variados grupos populacionais, especialmente entre idosos. Dados internacionais mostram que $5 \%$ a $25 \%$ da população idosa independente e $60 \%$ a $80 \%$ dos idosos institucionalizados apresentam deficiência ou insuficiência dessa vitamina. Embora a síntese de vitamina D esteja associada à exposição solar, a deficiência dessa vitamina é subdiagnosticada em países onde a radiação solar é considerada suficiente ${ }^{(16,21)}$.

A vitamina $D$ desempenha um papel importante na homeostasia do cálcio. Esse hormônio, juntamente com o paratormônio (PTH), atua na regulação da concentração de cálcio e fósforo no plasma ${ }^{(3)}$. Níveis insuficientes de vitamina $D$ estão associados a raquitismo em crianças e a osteomalácia em adultos, redução do cálcio sérico, elevação dos níveis de PTH, resultando em hiperparatireoidismo secundário, perda de massa óssea e, em alguns casos, osteoporose. Além disso, níveis insuficientes de vitamina $D$ estão sendo relacionados com outras patologias, incluindo doenças cardiovasculares, diabetes mellitus tipo 2, câncer de próstata e cólon, esclerose múltipla, doenças intestinais, entre outras ${ }^{(5,7,8,19)}$.

A vitamina $D 3$ é biotransformada para formar 25-hidroxivitamina $\mathrm{D}(25(\mathrm{OH}) \mathrm{D})$ e, sucessivamente, a forma ativa 1,25-di-hidroxivitamina $\mathrm{D}\left(1,25(\mathrm{OH})_{2} \mathrm{D}\right)$. A mensuração da vitamina D3 normalmente é realizada por meio da determinação dos níveis plasmáticos de $25(\mathrm{OH}) \mathrm{D}_{3}$, visto que esse metabólito possui meia-vida de algumas semanas e representa a forma de armazenamento da vitamina $D^{(11)}$. Por outro lado, as concentrações de 1,25(OH) D apresentam pequena variabilidade, mesmo em diferentes concentrações de vitamina $\mathrm{D} 3$, sendo mais relacionadas com alterações de função renal, além de possuir uma curta meia-vida de aproximadamente seis horas ${ }^{(17)}$. A 25-hidroxivitamina D2 $\left(25(\mathrm{OH}) \mathrm{D}_{2}\right)$ também pode estar presente, proveniente especialmente de fontes vegetais ${ }^{(11)}$. A vitamina D2 difere da vitamina $D 3$, pois possui uma ligação dupla entre carbono 22 e carbono 23 e um grupo metila em carbono $24^{(3)}$.

O interesse clínico na vitamina $D$ tem aumentado substancialmente nos últimos anos, resultado de sua associação com uma grande variedade de doenças e condições. Paralelo a isso, ocorreu um aumento significativo do número de análises laboratoriais, com relatos de crescimento na ordem de $100 \%$ ao ano $^{(4)}$. Dessa forma, existe uma demanda crescente por determinações de vitamina D. Os métodos utilizados nessas determinações devem ser capazes de diferenciar a $25(\mathrm{OH}) \mathrm{D}_{3}$ e $25(\mathrm{OH}) \mathrm{D}_{2}$ de outras formas de vitamina $D$, sendo a cromatografia líquida de alta eficiência (CLAE) o método preferencial(20). Entretanto, uma das principais limitações para o diagnóstico da hipovitaminose está relacionada com a falta de padrões de referência de normalidade ${ }^{(21)}$.

A maioria dos trabalhos publicados que descrevem a determinação de $25(\mathrm{OH}) \mathrm{D}_{3}$ e $25(\mathrm{OH}) \mathrm{D}_{2}$ em plasma por CLAE empregam separações em fase reversa com detectores fotométricos $^{(8,12,20)}$ ou seletivos de massas ${ }^{(7,15)}$. O emprego de detectores de arranjo de diodos permite a obtenção de dados espectrais, mantendo os custos operacionais e de aquisição da CLAE com detectores fotométricos e com sensibilidade suficiente para determinar as concentrações encontradas em amostras clínicas, quando associada a uma etapa de pré-concentração das amostras. A forma mais usual de preparação de amostras para determinação de $25(\mathrm{OH}) \mathrm{D}_{3}$ em plasma é a extração com solventes, com diversas etapas analíticas ${ }^{(8,12,20)}$. Esses procedimentos usualmente requerem utilização de padrões internos para obtenção de protocolos suficientemente robustos para aplicação em análises de rotina, sendo um número limitado de autores utilizando essa abordagem ${ }^{(7,15)}$.

Considerando a disponibilidade limitada de serviços analíticos que empreguem CLAE para determinação de $25(\mathrm{OH}) \mathrm{D}_{3}$ e $25(\mathrm{OH}) \mathrm{D}_{2}$ em nosso meio, o desenvolvimento e a validação de uma metodologia simples e robusta pode representar uma contribuição significativa para a qualificação dos serviços de diagnóstico laboratoriais no Brasil.

\section{Objetivos}

Desenvolver, validar e avaliar um método para determinação de níveis plasmáticos de $25(\mathrm{OH}) \mathrm{D}_{3}$ e $25(\mathrm{OH}) \mathrm{D}_{2}$ empregando CLAE com detector de arranjo de diodos (DAD).

\section{Materiais e métodos}

\section{Reagentes e soluções}

Albumina bovina fração $\mathrm{V}$ foi proveniente da Alamar Tecno-Científica Ltda (Diadema, São Paulo); metanol grau cromatográfico, da J. T. Baker (Xalostoc, México); álcool isopropílico, da Fmaia (Cotia, São Paulo); dodecafenona, $25(\mathrm{OH}) \mathrm{D}_{3}$ e $25(\mathrm{OH}) \mathrm{D}_{2^{\prime}}$ da Sigma Aldrich (St. Louis, Estados Unidos); hexano grau cromatográfico, da Mallinckrodt (Xalostoc, México); e água purificada foi obtida por meio 
de um sistema Elga Purelab Ultra da Elga Labwater (Lane End, Reino Unido).

O soro sintético foi preparado mediante a dissolução de $5 \mathrm{~g}$ de albumina em $100 \mathrm{ml}$ de água purificada. A mistura metanol:isopropanol foi preparada por meio da homogeneização de $80 \mathrm{ml}$ de metanol e $20 \mathrm{ml}$ de álcool isopropílico.

As soluções estoque individuais de $25(\mathrm{OH}) \mathrm{D}_{3}$ e $25(\mathrm{OH}) \mathrm{D}_{2}$ $(40 \mu \mathrm{g} / \mathrm{ml})$ foram preparadas com a diluição de $1 \mathrm{mg}$ dos respectivos compostos em $25 \mathrm{ml}$ de metanol; a solução estoque combinada de $25(\mathrm{OH}) \mathrm{D}_{3}$ e $25(\mathrm{OH}) \mathrm{D}_{2}(10 \mu \mathrm{g} / \mathrm{ml})$ foi preparada com a diluição de $2,5 \mathrm{ml}$ das soluções estoques individuais até $10 \mathrm{ml}$ com metanol. A partir da solução estoque combinada, foram preparadas soluções de trabalho nas concentrações $2.000,1.000,500,200$ e $100 \mathrm{ng} / \mathrm{ml}$ de $25(\mathrm{OH}) \mathrm{D}_{3}$ e $25(\mathrm{OH}) \mathrm{D}_{2}$ por meio de diluições com metanol, denominadas ST1, ST2, ST3, ST4 e ST5, respectivamente. A solução estoque de dodecafenona ( $1 \mathrm{mg} / \mathrm{ml}$ ) foi preparada com a diluição de $10 \mathrm{mg}$ de dodecafenona em $10 \mathrm{ml}$ de metanol. A solução de trabalho do padrão interno (PI) dodecafenona (PI, $100 \mu \mathrm{g} / \mathrm{ml}$ ) foi preparada diluindo $1 \mathrm{ml}$ da solução estoque com $9 \mathrm{ml}$ de metanol.

\section{Equipamentos}

Empregou-se um cromatógrafo líquido de alta eficiência Accela 600 com DAD contendo uma célula de fluxo de $5 \mathrm{~cm}$, controlado pelo programa ChromQuest 5.0, proveniente da Thermo Scientific (San Jose, Estados Unidos). A separação cromatográfica foi realizada em uma coluna ACE 5 C 18 com partículas de $5 \mu \mathrm{m}$ e dimensões de $150 \times$ 4,6 mm, proveniente da Advanced Chromatography Technologies (Aberdeen, Reino Unido).

\section{Preparação da fase móvel e condições cromatográficas}

A fase móvel foi preparada por meio da mistura de metanol grau cromatográfico e água purificada na proporção 80:20 volume por volume (v/v). A vazão dessa fase variou de $1,2 \mathrm{ml} / \mathrm{min}$ até $1,5 \mathrm{ml} / \mathrm{min}$ em 21 minutos, permanecendo constante em 1,5 $\mathrm{ml} / \mathrm{min}$ até o final da análise, 23 minutos. A coluna foi mantida a $40^{\circ} \mathrm{C}$ durante todo o procedimento. A detecção foi realizada em $263 \mathrm{~nm}$ com a aquisição de espectros de varredura entre 210 e $380 \mathrm{~nm}$.

\section{Preparação das amostras cromatográficas}

Em um microtubo de polipropileno, foram adicionados $700 \mu \mathrm{l}$ de amostra (solução calibradora ou plasma),
$500 \mu \mathrm{l}$ da mistura metanol:isopropanol e $100 \mu \mathrm{l}$ da solução de trabalho do PI. A mistura resultante foi homogeneizada em vórtex por 30 segundos e mantida em repouso por 10 minutos. Após, uma alíquota de $1 \mathrm{ml}$ dessa mistura foi transferida para um tubo de tampa rosca, no qual foram adicionados $4 \mathrm{ml}$ de hexano, seguido de nova homogeneização em vórtex por 30 segundos e centrifugação a $2.500 \mathrm{~g}$ por 10 minutos. Uma alíquota de 3,5 ml da fração orgânica foi transferida para um tubo de evaporação e o procedimento de extração foi repetido com outro volume de $4 \mathrm{ml}$ hexano, sendo uma alíquota de $3,5 \mathrm{ml}$ da fração orgânica adicionada ao tubo de evaporação. Este foi mantido a $40^{\circ} \mathrm{C}$ sob leve corrente de ar até a completa evaporação do solvente. $\mathrm{O}$ resíduo seco foi retomado com $150 \mu$ l de fase móvel e uma alíquota de $50 \mu$ foi injetada no sistema de cromatografia.

\section{Curva de calibração}

As soluções calibradoras foram preparadas por meio da diluição de $100 \mu \mathrm{l}$ das soluções de trabalho de $25(\mathrm{OH}) \mathrm{D}_{3} \mathrm{e}$ $25(\mathrm{OH}) \mathrm{D}_{2}$ com $900 \mu \mathrm{l}$ da solução de albumina $5 \%$, resultando em calibradores nas concentrações 200, 100, 50, 20 e $10 \mathrm{ng} / \mathrm{ml}$. Para a construção da curva de calibração, foi utilizada a média de cinco determinações de cada calibrador, que foram preparadas segundo o item Preparação das amostras. A curva de calibração foi construída mediante $o$ estabelecimento da correlação entre razão das áreas dos picos referentes a $25(\mathrm{OH}) \mathrm{D}_{3}$ e $25(\mathrm{OH}) \mathrm{D}_{2}$ com área do $\mathrm{PI}$ por meio de regressão linear ponderada, com fator ponderal $1 / \times$. A curva foi avaliada com base no coeficiente de determinação $\left(r^{2}\right)$. Curvas de calibração diárias usando as mesmas concentrações (medidas únicas por concentração) foram analisadas em cada lote de amostras de validação e autênticas.

\section{Ensaios de precisão e exatidão}

A precisão e a exatidão do método foram avaliadas por meio de análises de amostras calibradoras contendo $25(\mathrm{OH}) \mathrm{D}_{3}$ e $25(\mathrm{OH}) \mathrm{D}_{2}$ nas concentrações de 160 (controle de qualidade alto [CQA]), 80 (controle de qualidade médio [CQM]) e $15 \mathrm{ng} / \mathrm{ml}$ (controle de qualidade baixo [CQB]). As análises foram realizadas em triplicata e repetidas em cinco dias diferentes. As precisões intraensaios e interensaios foram calculadas pela análise de variância (ANOVA) usando "dia" como viável agrupadora e expressas como coeficiente de variação percentual (CV\%). A exatidão foi calculada pela percentagem dos valores encontrados em relação aos valores nominais de concentração. $O$ critério de aceitação 
para exatidão foram valores $\pm 15 \%$ do valor nominal e para precisão, CV\% máximo de $15 \%{ }^{(18)}$.

\section{Limite de quantificação}

Uma amostra controle na concentração do menor calibrador $(10 \mathrm{ng} / \mathrm{ml})$ foi incluída nos experimentos de precisão e exatidão, sendo processada em triplicata em três dias diferentes (controle de qualidade no limite de quantificação [CQLQ]). O critério de aceitação para o limite de quantificação nessa concentração foi exatidão $\pm 20 \%$ do valor nominal e CV máximo de $20 \%{ }^{(18)}$.

\section{Eficiência da extração}

A eficiência da extração foi determinada comparando a área dos picos obtidos na análise das amostras de controle de qualidade baixo e médio nos experimentos de precisão e exatidão com as obtidas em soluções metanólicas em concentrações correspondentes à recuperação completa, medidas em triplicata em três dias diferentes. A eficiência da extração foi expressa com porcentagem da quantidade existente na solução, que referencia que foi recuperada pelo procedimento de extração.

\section{Aplicação do método}

O método foi aplicado para avaliar as concentrações plasmáticas de $25(\mathrm{OH}) \mathrm{D}_{3}$ e $25(\mathrm{OH}) \mathrm{D}_{2}$ em um grupo de 32 indivíduos institucionalizados em um lar de longa permanência de idosos, localizado no Vale do Rio dos Sinos. $O$ sangue venoso coletado foi acondicionado em tubos contendo ácido etilenodiaminotetracético (EDTA) como anticoagulante e o plasma foi separado e armazenado a $-20^{\circ} \mathrm{C}$ até a análise. $\mathrm{O}$ estudo foi aprovado pelo Comitê de Ética em Pesquisa da FEEVALE (atendendo as diretrizes e as normas de pesquisa com seres humanos - Resolução 196/96 do Conselho Nacional de Saúde [CNS]) e todos os participantes ou seus cuidadores assinaram um termo de consentimento livre e esclarecido.

\section{Resultados e discussão}

Diversas técnicas para determinação da vitamina $D$ vêm sendo utilizadas, entretanto, a CLAE tem sido considerada o método de preferência para determinação de $25(\mathrm{OH}) \mathrm{D}_{3}$ e $25(\mathrm{OH}) \mathrm{D}_{2}$ em plasma. Uma vantagem significativa dessa metodologia é a possibilidade de separar e quantificar, de forma independente, $25(\mathrm{OH}) \mathrm{D}_{3}$ e $25(\mathrm{OH}) \mathrm{D}_{2}$. Contudo, a maior parte dos trabalhos publicados empregou preparações de amostras complexas ou não utilizaram padronização interna, o que reduz sua aplicabilidade prática ${ }^{(12,20)}$.

No presente estudo foi possível obter uma separação adequada dos metabólitos de vitamina $D$, bem como do PI dodecafenona, em um tempo de análise aceitável. A $25(\mathrm{OH}) \mathrm{D}_{3}$ apresentou tempo de retenção médio de 12,8 minutos, enquanto a $25(\mathrm{OH}) \mathrm{D}_{2}, 14,2$ minutos. O Pl elui em 20,9 minutos, com total de análise cromatográfica de 24 minutos. A Figura apresenta cromatogramas típicos do método obtidos em nosso estudo. Em todas as análises, os picos referentes aos analitos foram avaliados com respeito a sua pureza espectral e sua similaridade com os espectros de absorção de referência, por meio de rotinas disponíveis no sistema CLAE-DAD, e não foram observados interferentes demonstrando a seletividade do método.

Vários métodos têm sido desenvolvidos para determinar esses metabólitos utilizando CLAE, como os descritos por Turpeinen et al. ${ }^{(21)}$ e Olkowski et al. ${ }^{(13)}$, os quais empregaram extração líquido-líquido. Uma desvantagem dos métodos em questão foi não ter utilizado $\mathrm{Pl}$, que é fundamental para a confiabilidade do método. Em especial, os cromatogramas típicos do estudo proposto por Olkowski et al.(13) tiveram muitos interferentes e picos sem uma separação adequada.

A preparação das amostras empregadas por Lensmeyer et al. ${ }^{(8)}$ foi mais complexa, utilizando extração em fase sólida com cartucho Strata-X, o que resulta em custos e tempo de execução maiores. Saenger et al. ${ }^{(16)}$ utilizaram cromatografia líquida associada a detectores de massas em tandem (LC-MS-MS) e, como $\mathrm{Pl}, 0 \Delta$ 9-tetrahydrocannabinol (THC)- $\mathrm{D}_{3}$ composto caro e de difícil acesso.

A principal vantagem do presente estudo foi a utilização de um PI de fácil aquisição e preço acessível. Outros aspectos a serem destacados são a capacidade de quantificar $25(\mathrm{OH}) \mathrm{D}_{2}$ e $25(\mathrm{OH}) \mathrm{D}_{3}$ e o emprego de extração líquido-líquido com hexano, que foi relativamente simples, contribuindo para a diminuição dos custos no processamento das amostras.

Comparando o nosso estudo com o método desenvolvido por Turpeinen et al. ${ }^{(21)}$, houve significativa redução do tempo de análise cromatográfica, de 30 para 24 minutos. Trata-se de um ganho considerável de tempo em análises de rotina, além da diminuição de volume de fase móvel empregada em cada análise. O método obteve bons resultados ao ser comparado com outros estudos, recuperação alta, boa linearidade e reprodutibilidade. A preparação das amostras foi simples e fácil para as análises de rotina. 

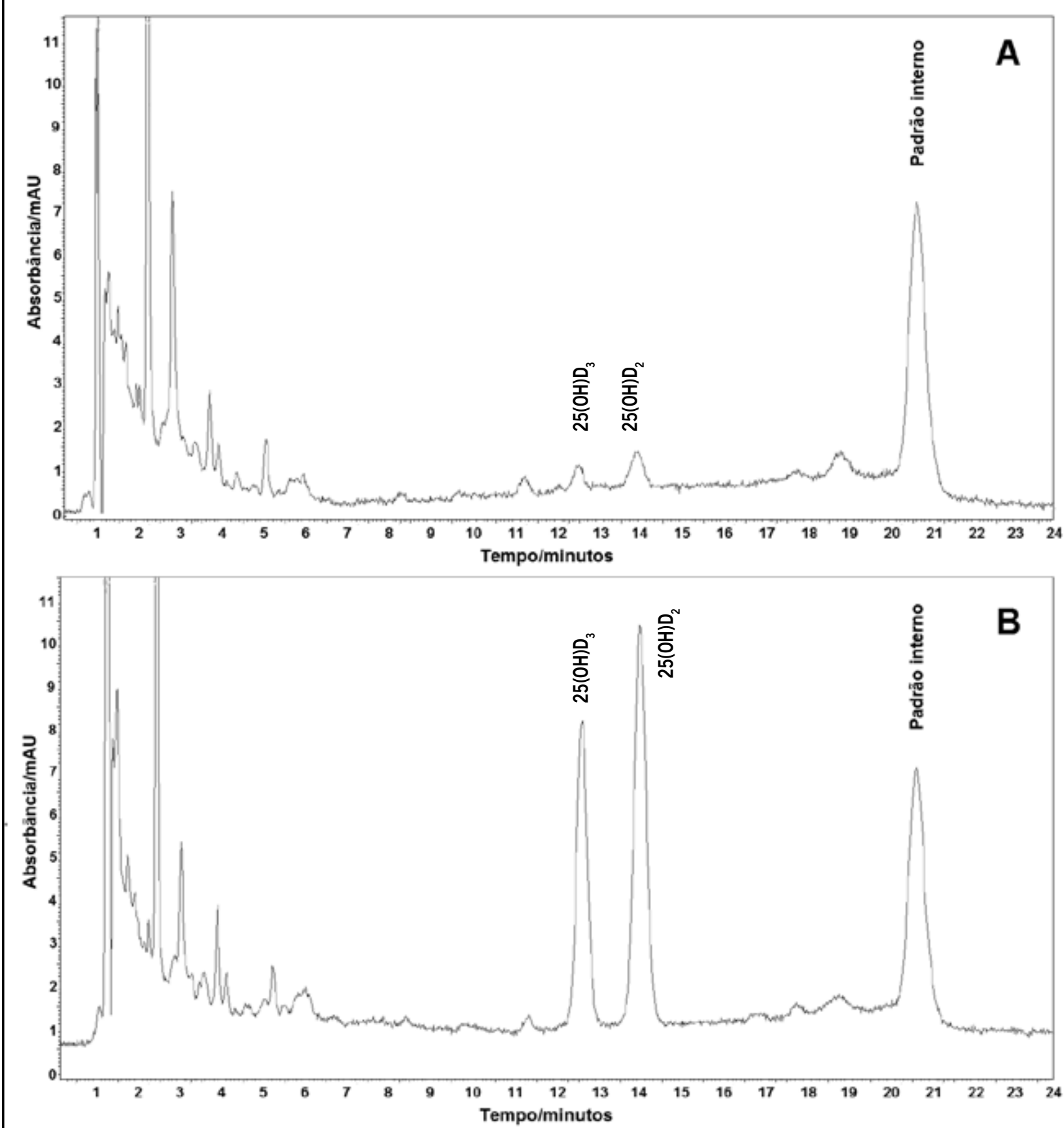

Figura - Cromatogramas obtidos com o método. (A) amostra controle contendo $25(\mathrm{OH}) \mathrm{D}_{3}$ e $25(\mathrm{OH}) \mathrm{D}_{2}$ na concentração de $10 \mathrm{ng} / \mathrm{ml}$; (B) amostra controle contendo $25(\mathrm{OH}) \mathrm{D}_{3}$ e $25(\mathrm{OH}) \mathrm{D}_{2}$ na concentração de $200 \mathrm{ng} / \mathrm{ml}$

As curvas de calibração obtidas apresentaram linearidade adequada, com $r^{2}$ superior a 0,99 . Os dados de validação do método são apresentados na Tabela 1. A precisão intraensaios esteve entre $6,5 \%$ e $9,2 \%$ para $25(\mathrm{OH}) \mathrm{D}_{3} \mathrm{e}$ entre $3,7 \%$ e $8,7 \%$ para $25(\mathrm{OH}) \mathrm{D}_{2}$. A precisão interensaios esteve entre $2,9 \%$ e $6 \%$ para $25(\mathrm{OH}) \mathrm{D}_{3}$ e entre $4 \%$ e $4,5 \%$ para $25(\mathrm{OH}) \mathrm{D}_{2}$, demonstrando adequada repetibilidade do método. A exatidão foi determinada entre $98,4 \%$ e 107,5\%, também dentro dos critérios de aceitação para métodos bioanalíticos preconizados por Shah et al. ${ }^{(19)}$.
O limite de quantificação (LQ) foi determinado a partir da avaliação da precisão e da exatidão do calibrador de menor concentração avaliado. O limite inferior de quantificação foi de $10 \mathrm{ng} / \mathrm{ml}$, com precisão intraensaios de 9,2\% para $25(\mathrm{OH}) \mathrm{D}_{3}$ e $8,7 \%$ para $25(\mathrm{OH}) \mathrm{D}_{2}$. A precisão interensaios foi de $5,8 \%$ para $25(\mathrm{OH}) \mathrm{D}_{3}$ e $4,2 \%$ para $25(\mathrm{OH}) \mathrm{D}_{2^{\prime}}$ e a exatidão de $104 \%$ e $104,5 \%$, respectivamente. Esse limite de quantificação é comparável entre os relatados anteriormente por outros autores que empregaram CLAE. A recuperação do procedimento de extração foi elevada, entre 76,2\% e 83,6\%. 
Tabela 1 Parâmetros de validação do método

\begin{tabular}{|c|c|c|c|c|c|c|}
\hline Analito & $\begin{array}{l}\text { Amostra } \\
\text { controle }\end{array}$ & $\begin{array}{l}\text { Concentração } \\
\text { nominal ( } \mu \mathrm{g} / \mathrm{ml})\end{array}$ & $\begin{array}{l}\text { Intradias } \\
\text { (CV \%) }\end{array}$ & $\begin{array}{l}\text { Interdias } \\
\text { (CV \%) }\end{array}$ & $\begin{array}{c}\text { Exatidão } \\
(\%)\end{array}$ & $\begin{array}{l}\text { Rendimento da } \\
\text { extração }(\%)\end{array}$ \\
\hline \multirow{4}{*}{$25(\mathrm{OH}) \mathrm{D}_{3}$} & CQLQ & 10 & 8,9 & 9,1 & 107,5 & - \\
\hline & CQB & 15 & 9,2 & 5,8 & 104,1 & 76,2 \\
\hline & CQM & 80 & 3,7 & 2,9 & 103,2 & 83,6 \\
\hline & CQA & 160 & 6,5 & 6 & 98,4 & - \\
\hline \multirow{4}{*}{$25(\mathrm{OH}) \mathrm{D}_{2}$} & CQLQ & 10 & 4,9 & 5,8 & 104,5 & - \\
\hline & $C Q B$ & 15 & 8,7 & 4,2 & 104,5 & 82,6 \\
\hline & CQM & 80 & 3,7 & 4 & 102,8 & 81,3 \\
\hline & CQA & 160 & 8 & 4,5 & 100,1 & - \\
\hline
\end{tabular}

CV: coeficiente de variação; CQLQ: controle de qualidade no limite de quantificação; CQB: controle de qualidade baixo; CQM: controle de qualidade médio; $C Q A:$ controle de qualidade alto.

As soluções e as amostras contendo $25(\mathrm{OH}) \mathrm{D}_{2} \mathrm{e}$ $25(\mathrm{OH}) \mathrm{D}_{3}$ mostraram-se estáveis após ciclos de congelamento e descongelamento no decorrer do método. A estabilidade de bancada e a longo prazo não foi avaliada, uma vez que existem diversos estudos comprovando a estabilidade frente a várias situações de rotina do laboratório. Um estudo sobre a estabilidade das vitaminas $25(\mathrm{OH}) \mathrm{D}_{2} \mathrm{e}$ $25(\mathrm{OH}) \mathrm{D}_{3}$ foi realizado por Lewis e Elder ${ }^{(9)}$, os quais analisaram cinco amostras submetidas a diferentes situações. Estas foram expostas oito dias à temperatura ambiente sob várias condições e uma breve exposição à luz ultravioleta artificial. Os autores concluíram que sob condições extremas $25(\mathrm{OH}) \mathrm{D}_{3}$ e $25(\mathrm{OH}) \mathrm{D}_{2}$ são excepcionalmente estáveis, exceto quando submetidos à exposição prolongada ao sol sem proteção $\operatorname{direta}^{(8)}$. Wielders e Wijnberg ${ }^{(23)}$ também testaram a estabilidade de $25(\mathrm{OH}) \mathrm{D}_{3}$ em oito amostras de sangue sob condições laboratoriais de rotina. Além disso, testaram vários ciclos de congelamento e descongelamento. As concentrações de $25(\mathrm{OH}) \mathrm{D}_{3}$ parecem ser extremamente estáveis em temperatura ambiente e sob condições comuns encontradas na rotina do laboratório. A estabilidade a longo prazo de $25(\mathrm{OH}) \mathrm{D}_{3}$ foi estudada por Joergensen et al.(7), que analisaram amostras colhidas de pacientes com diabetes mellitus tipo 1 armazenando-as por cinco, 10, 15, 20 e 25 anos. Essas amostras foram analisadas por CLAE e não houve diferença significativa entre os níveis de vitamina D3 após o passar dos anos.

A síntese de vitamina D3 é proporcional à área exposta à luz solar e sofre influência de fatores ambientais, como pouca exposição à luz ultravioleta B (UVB), países de pouca insolação (alta latitude) e quantidade de nuvens ou camada de ozônio, e de fatores relacionados com hábitos do próprio indivíduo, como uso de protetor solar, exposição direta aos raios solares, uso de roupas que cubram grande parte do corpo, idade avançada, pigmentação da pele, doenças que alteram o metabolismo da $25(\mathrm{OH}) \mathrm{D}$ e $1,25(\mathrm{OH}) \mathrm{D}_{3}$ (doenças renais, doenças do trato gastrintestinal etc.) e diminuição da disponibilidade da vitamina D3 (obesidade e aleitamento materno) $)^{(2,7)}$.

Até o momento, não existe um consenso sobre valores de referência de vitamina $D$, tampouco $25(\mathrm{OH}) \mathrm{D}_{3}$, sendo os níveis plasmáticos propostos por diversos autores variados entre 10 a $40 \mathrm{ng} / \mathrm{ml}^{(1,4,9,10,13,16,19,21,22)}$. Dessa forma, o presente estudo utilizou valores de referência entre < $30 \mathrm{ng} / \mathrm{ml}$ para indicar a deficiência de vitamina D nos pacientes analisados. Como nosso limite de quantificação foi de $10 \mathrm{ng} / \mathrm{ml}$, o método tem a capacidade de detectar concentrações plasmáticas baixas de $25(\mathrm{OH}) \mathrm{D}_{3}$.

O método desenvolvido foi aplicado a 32 idosos institucionalizados, entre eles sete homens $(21,9 \%)$ e 25 mulheres $(78,1 \%)$ na faixa etária de 64 a 95 anos. As concentrações encontradas foram de 10,1 a $32,4 \mathrm{ng} / \mathrm{ml}$ e a média de concentrações encontradas, de $21 \mathrm{ng} / \mathrm{ml}$. As mulheres tinham valores de $25(\mathrm{OH}) \mathrm{D}_{3}$ de $10,1 \mathrm{a}$ $32,4 \mathrm{ng} / \mathrm{ml}$ e os homens de 10,7 a $26,5 \mathrm{ng} / \mathrm{ml}$, não havendo diferenças significativas entre os resultados encontrados. Todos os pacientes foram considerados deficientes de vitamina D. As concentrações de $25(\mathrm{OH}) \mathrm{D}_{3}$ estão agrupadas na Tabela 2. Não se identificou $25(\mathrm{OH}) \mathrm{D}_{2}$ em nenhuma das amostras avaliadas. Verificou-se que os idosos institucionalizados apresentam deficiência de vitamina D. Essa população é mais suscetível a hipovitaminose por vários motivos, como exposição menor ao sol, capacidade de produção cutânea de vitamina D3 reduzida, alimentação inadequada, absorção gastrointestinal reduzida e administração de diversos 
fármacos que podem interferir na absorção ou metabolização da vitamina D3, além de uma maior frequência de comprometimento renal| ${ }^{(13,14,16)}$.

\section{Resultados encontrados para $25(\mathrm{OH}) \mathrm{D}_{3}$}

Tabela 2 no grupo de idosos avaliados

\begin{tabular}{|c|c|c|c|}
\hline Amostra & $\begin{array}{c}25(\mathrm{OH}) \mathrm{D}_{3} \\
(\mathrm{ng} / \mathrm{ml})\end{array}$ & Amostra & $\begin{array}{c}25(\mathrm{OH}) \mathrm{D}_{3} \\
(\mathrm{ng} / \mathrm{ml})\end{array}$ \\
\hline 1 & 10,7 & 17 & 27,2 \\
\hline 2 & 29,3 & 18 & 19,4 \\
\hline 3 & 10,8 & 19 & 19,3 \\
\hline 4 & 20,6 & 20 & 13,5 \\
\hline 5 & 11,7 & 21 & 19,6 \\
\hline 6 & 25,4 & 22 & 20,9 \\
\hline 7 & 16,5 & 23 & 23,9 \\
\hline 8 & 10,1 & 24 & 21,2 \\
\hline 9 & 22 & 25 & 22,5 \\
\hline 10 & 19,7 & 26 & 14 \\
\hline 11 & 32,4 & 27 & 28 \\
\hline 12 & 20,4 & 28 & 16,5 \\
\hline 13 & 28,6 & 29 & 16 \\
\hline 14 & 31,7 & 30 & 23,4 \\
\hline 15 & 18,6 & 31 & 29,6 \\
\hline 16 & 25 & 32 & 22,8 \\
\hline Média & 21 & & \\
\hline & & & \\
\hline
\end{tabular}

Cerca de um bilhão de pessoas em todo o mundo apresenta hipovitaminose. Essa deficiência é mais comum na Europa quando comparada com os Estados Unidos, visto que $40 \%$ dos europeus apresentam deficiência de vitamina D3 no inverno. Dados europeus demonstraram que a deficiência de vitamina D3 é surpreendentemente mais comum em indivíduos que vivem em países com maior radiação solar, como Itália, Grécia e Espanha, em comparação com os países onde a exposição solar é considerada inadequada ${ }^{(21)}$.

Saraiva et al. ${ }^{(17)}$ avaliaram concentrações plasmáticas de $25(\mathrm{OH}) \mathrm{D}_{3^{\prime}}$ PTH e cálcio ionizado em 177 idosos institucionalizados ( 125 mulheres e 52 homens) e 243 ambulatoriais (168 mulheres e 75 homens) moradores da cidade de São Paulo. Nesse estudo, $71,2 \%$ do grupo institucionalizado e $43,8 \%$ do grupo ambulatorial possuíam valores de $25(\mathrm{OH}) \mathrm{D}$ menores que $20 \mathrm{ng} / \mathrm{ml}$, apresentando as mulheres valores mais baixos que os homens. Outro estudo foi realizado na cidade de Belo Horizonte, com 180 pacientes ambulatoriais, no qual os níveis de $25(\mathrm{OH}) \mathrm{D}_{3}$ foram mensurados por CLAE. Entre os pacientes que não faziam uso de suplementação de vitamina D3, a prevalência de insuficiência foi de $42,4 \%$, e entre os pacientes que faziam uso de suplementação com apresentações e doses variadas, $27 \%$ apresentavam deficiência da vitamina D3 ${ }^{(19)}$.

\section{Conclusão}

Um método para a determinação de $25(\mathrm{OH}) \mathrm{D}_{3}$ e $25(\mathrm{OH}) \mathrm{D}_{2}$ em plasma por meio de cromatografia CLAE-DAD foi desenvolvido e validado. A preparação das amostras foi simples e rápida, com base em extração líquido-líquido com hexano. A calibração empregou padronização interna. $O$ método foi preciso e exato, com sensibilidade adequada para a determinação de $25(\mathrm{OH}) \mathrm{D}_{3}$ e $25(\mathrm{OH}) \mathrm{D}_{2}$ nas concentrações clinicamente relevantes, permitindo uma determinação confiável para laboratórios que disponham de equipamentos de CLAE.

\section{Referências}

1. BAYER, W. Vitamin D: the all-rounder. Dialog. Special edition vitamin D. p. 1-12, 2010.

2. BUENO, A. L.; CZEPIELEWSKI, M. A. A importância do consumo dietético de cálcio e vitamina $D$ no crescimento. J Pediatr, v. 84, n. 5, p. 386-94, 2008.

3. GOODMAN, L. S.; GILMAN, A. As bases farmacológicas da terapêutica. Rio de Janeiro: Mc-Graw-Hill Interamericana editores, 2005.

4. HEALY, M. Vitamin D in the clinical environment an overview. Dialog. Special edition vitamin D, p. 5, 2010.

5. HOLICK, M. F. Vitamin D: a D-Lightful health perspective. Nutr Rev, v. 66, n. 10, p. S182-94, 2008.
6. HOLICK, M. F. et al. The endocrine society's Clinical Guidelines 2011. Disponível em: < http://www.endosociety.org/guidelines/final/upload/final-standalonevitamin-d-guideline.pdf>. Acesso em: out. 2011.

7. JOERGENSEN, C. et al. Vitamin D levels and mortality in type 2 diabetes. Diabetes Care. v. 33, n.10, p. 223843, 2010.

8. LENSMEYER, L. G. et al. HPLC method for 25-hydroxyvitamin D measurement: comparison with contemporary assays. Clin Chem, v. 52, n. 6, p. 1120-6, 2006.

9. LEWIS, J. G.; ELDER, P. A. Serum 25-Oh vitamin D2 and D3 are stable under exaggerated conditions. Clin Chem, v. 54, n.11, p.1931-2, 2008. 
10. LI, H. et al. A prospective study of plasma vitamin D metabolites, vitamin $\mathrm{D}$ receptor polymorphisms, and prostate cancer. PLOS Med, v. 4, n. 3, p. 562-71, 2007.

11. MAIA, M.; MAEDA, S. S.; MARÇON, C. Correlação entre fotoproteção e concentrações de 25-hidroxivitamina D e paratormônio. An Bras Dermatol, v. 82, n. 3, p. 233-7, 2007.

12. MIDASCH, O. 25-OH-vitamin $\mathrm{D}_{3} / \mathrm{D}_{2}$ reagent kits for $\mathrm{HPLC}$ and LC-MS/MS analysis. Dialog. Special edition vitamin D, p. 3-4, 2010.

13. OLKOWSKI, A. A.; ARANDA-OSORIO, G.; MCKINNON, J. Rapid HPLC method for measurement of vitamin $D_{3}$ and $25(\mathrm{OH}) \mathrm{D}_{3}$ in blood plasma. Int J Vitam Nutr Res, v. 73, n. 1, p. 15-8, 2003.

14. PEDROSA, M. A. C.; CASTRO, M. L. Papel da vitamina D na função neuromuscular. Arq Bras Endocrinol Metab, v. 49, n. 4, p. 495-501, 2005.

15. PREMAOR, M. O.; FURLANETTO, T. W. Hipovitaminose $\mathrm{D}$ em adultos: entendendo melhor a apresentação de uma velha doença. Arq Bras Endocrinol Metab, v. 50, n.1, p. 25-37, 2006.

16. SAENGER, A. K. et al. Quantification of Serum 25-hydroxyvitamin D2 and D3 using HPLC-Tandem mass spectrometry and examination of reference intervals for diagnosis of vitamin D deficiency. Clin Chem, v. 125, p. 914-20, 2005.

17. SARAIVA, G. L. et al. Prevalência de deficiência, insuficiência de vitamina $D$ e hiperparatiroidismo secundário em idosos institucionalizados e moradores na comunidade da cidade de São Paulo, Brasil. Arq Bras Endocrinol Metab, v. 51, n. 3, p. 437-42, 2007.

18. SCHUCH, N. J.; GARCIA, V. C.; MARTINI, L. A. Vitamina D e doenças endocrinometabólicas. Arq Bras Endocrinol Metab, v. 53, n. 5, p. 625-33, 2009.

19. SHAH, V. P. et al. Bioanalytical method validation - a revisit with a decade of progress. Pharm Res, v. 17, n. 12 p. 1551-7, 2000.

20. SILVA, B. C. C. et al. Prevalência de deficiência e insuficiência de vitamina D e sua correlação com PTH, marcadores de remodelação óssea e densidade mineral óssea, em pacientes ambulatoriais. Arq Bras Endocrinol Metab, v. 52, n. 3, p. 482-8, 2008.

21. TURPEINEN, U.; HOHENTHAL, U.; STENMAN U. Determination of 25-hydroxyvitamin $D$ in serum by HPLC and immunoassay. Clin Chem, v. 49, n. 9, p. 1521-4, 2003.

22. UNGER, M. D. Determinação dos níveis séricos de vitamina $D$ em uma amostra de indivíduos saudáveis da população brasileira. São Paulo, 2009. Tese (doutoramento) - Faculdade de Medicina, Universidade de São Paulo.

23. WIELDERS, J. P. M.; WIJNBERG, F. A. Preanalytical stability of $25(\mathrm{OH})$ - Vitamin $\mathrm{D}_{3}$ in human blood or serum at room temperature: solid as a rock. Clin Chem, v. 55, n. 8, p. 1584-95, 2009. 